\title{
9. Dynamics of media hype: Interactivity of the media and the public ${ }^{*}$
}

\author{
IkJae Chung
}

Vasterman, Peter (ed.), From Media Hype to Twitter Storm. News Explosions and Their Impact on Issues, Crises, and Public Opinion. Amsterdam University Press, 2018

DOI: $10.5117 / 9789462982178 / \mathrm{CHOg}$

\begin{abstract}
This chapter tries to integrate two theoretical components, media hype and social issue amplification, to understand the dynamics of social issue evolution in the internet environment. Due to the growing role of the public online, the amplification process is changing. By analysing a risk issue related to a new high-speed railway tunnel project in South Korea, the interactivities between the media and the public are explored using online data from major newspapers and messages on websites of public and non-profit agencies in the country. The results show that neither the media alone, nor the public by themselves can make a social issue develop into a 'storm'. Extended media coverage can, however, attract strong public concern and vice versa, amplifying the issue.
\end{abstract}

Keywords: media hype, issue amplification, risk communication, online interactivity

\section{Introduction}

There is not enough media space for all the accidents or social events in our daily lives. Many social issues receive no print or online media attention. It is natural to expect that mega-stories such as the September 11 attacks, the 2011 Japan Earthquake, and international economic crises attract extended media coverage. However, some local issues highlighted by newspapers or online media quite often develop into news stories with nationwide interest. It is not unusual for a minor problem, once exposed to media, to trigger intense public concern far beyond its real impact. An unusually heightened level of media coverage is described as a media frenzy (Sabado, 1991) or 
media storm (Boydstun, 2014). Extended media coverage can attract strong public concern and vice versa; or, they work together to create a hoopla (Abbott, 2001). Individuals and organizations with a vested interest in an issue provide more information to the media; then the media is inclined to intensify their attention to the issue and widen their focus on similar issues.

The idea of media as information providers and agenda-setters is hardly new. Focused media coverage can have a strong impact on public awareness and reaction to social issues by transmitting and sharing information about them. However, it is not easy to find empirical analyses for explaining interactivities of the media and the public in the process of making a hype. This chapter reviews the role of online media and newspapers in communicating and shaping social issues by applying the 'media hype' conceptual framework (Vasterman, 2005) to an environmental controversy over a tunnel construction for a high-speed railway project in Seoul, South Korea (hereafter Korea). It is not intended to answer the basic question of whether mass media make public agenda or policy change, but rather explores the interactive dynamics of mass media and the public converging on the environmental risk issue under a special communication environment in which the issue was hyped by media and amplified by the public. This chapter examines not-fully-answered questions in risk communication; specifically, how does a risk issue develop into a hype? How does mass media work in a dynamic process of amplifying social attention to the issue? The answers to these research questions are elaborated by using time-series data from reply comments or talkbacks attached to major newspaper articles and messages uploaded onto websites of public and non-profit agencies in Korea.

\section{Theoretical background}

This chapter is based on two theoretical components, media hype and social issue amplification, to understand the dynamics of social issue evolution in the internet environment. The former highlights the role of media in communicating and transmitting information about a key event to the general public. In particular, media hype underlines media's active role in defining and constructing social problems. The latter focuses on the process of amplifying social issues as the public and social stations ${ }^{1}$ interact with each other leading to intensive attention and concern for them. However, neither the media alone, nor the public by themselves can cause any social issue to develop into a 'storm'. 
The role of the media is increasingly influential in the public agendasetting process because most of our understanding and knowledge about social issues or public problems comes not from direct personal experience, but from diverse online and traditional media. Existing research shows that the effects of media as information providers and agenda-setters are minimal for those social issues that individuals have direct experience of. However, they have a significant effect on issues that people have no knowledge of or experience only indirectly, because the public has a need for information and orientation in this regard. The media is more influential on those who perceive an issue as personally relevant or interesting (Thomson \& Dininni, 2005). This means that mass media do not simply disseminate information and cover the reality as it is; rather, they add additional meanings to information or create a story acting as a 'meaning-making institution' (Finlay \& Faulkner, 2005). In particular, extended and focused media coverage not only attracts strong public attention, but also leads to amplified social concern over the issue in question (Chung, 2011; Kapserson, 1988; Vasterman, 2005). There is a positive feedback loop, or a reinforcing relation between mass media and the public in producing an unusually heightened level of media coverage and social attention.

With regard to risk communication, in particular, the existing research has focused on mass media as a contributing factor in amplifying risk (Bakir, 2005; Eldridge et al., 2003; Flynn et al., 1998, 2001; Susarl, 2003). According to survey results by Frewer et al. (2002) for genetically modified (GM) food in United Kingdom, people's risk perception was significantly influenced by the volume and the content of media reporting. Risk perception associated with GM foods was amplified as reporting levels reached the highest level. In particular, a novel hazard with limited information tends to influence public perception through the risk amplification process, more than an established hazard that people are already exposed to or familiar with. Diminished media coverage was followed by a lower level of risk perception with regard to GM foods. Public perception of 'unfriendly' places like nuclear facilities is intensified by media reports on accidents. People's negative perceptions, avoidance behaviour, and distrust of the facility's management lower property values near the facility site (Flynn et al., 1998, 2001). In addition to newspapers (Murdock et al., 2003) and broadcast media (Bakir, 2005), dramatized portrayals of risks and disasters in movies and television shows have an influence on public awareness and perceptions about risks (Bahk et al., 2000; Leiserowitz, 2004).

In the internet environment, where the volume and the scope of risk messages are much larger than in the traditional media, a small number 
of active message writers, even one-person web campaigns, can effectively mobilize public attention for a risk (Rodrigue, 2001; Krimsky, 2007). Due to its universal accessibility and interactive openness, talkbacks and comments on media messages provide a large public space for active participation, which can lead to policy changes as a result of issue amplification (Chung, 2011). However, empirical examination of risk amplification is rare because it is not easy to predict whether a risk event triggers amplification or not, and because planned data collection assessing risk perception is difficult without prior knowledge of the risk event (Frewer, Miles \& Marsh. 2002: 701). In particular, it is very difficult to analyse the process of risk amplification and changes in risk perception because risk events, media attention, and risk perception interact with each other contemporaneously.

As the media dependency model underlines the interrelation between the media and the public (Ball-Rokeach \& DeFleur, 1976), it is hardly surprising that most of our knowledge and information is acquired through mass media. Mass media as information providers or transmitters not only cover or report the real world as objective incidents, but also create or make social issues as subjective construction. Journalism's self-interest and professional practice in the business area could result in disproportional coverage of a certain issue. Vasterman (2005a) reviews a series of acts of senseless violence through an analytical lens of media hype, which is defined as a self-reinforcing process of media in reporting a specific event. Abnormal news waves caused by media hype contradicts the assumption that the amount of media coverage indicates the importance of a social issue (Kepplinger \& Habermeier, 1995: 389).

A media-generated news wave, or self-inflating media coverage, can attract intensive public attention and have a significant influence on the agenda-setting process. Furthermore, policymakers who, influenced by media hype, take hasty actions could find that their policies are built on quicksand (Vasterman, 2005a: 510). However, other studies show that media hypes have limited and diffuse impact on the process. Media hypes gain minimal, if any, political influence insofar as they are used strategically by politicians to forward their agenda (Wien \& Elmelund-Præstekær, 2009). Based on five case studies, Elmelund-Præstekær and Wien (2008: 254) argue that they could not find any convincing evidence that media hypes cause political action at the national level. Media hypes were most politically significant in providing political actors with windows of opportunity to present themselves and their policies. Instead, the media function like a lighthouse, shedding light on existing political activities (Ibid: 255). 


\section{Key event}

The national project to build a tunnel through Mt. Cheonseong began in 2002 and was completed in 2010. The $13.3 \mathrm{~km}$-long tunnel carries the highspeed railway that links Seoul, the capital city, and Busan, the second largest city on Korea's southeastern coast. The project was interrupted at least four times by environmental groups asserting that the construction and the high-speed train would harm the mountain ecosystem, including thirty endangered species. In particular, an active environmentalist, a Buddhist nun named 'Jiyul', argued that the project posed a threat to the salamander habitat as it would result in the marshes on the mountain drying up. She participated in four hunger strikes since the tunnel construction began in June 2002. Environmentalists' activities, such as a class action suit on behalf of the salamander, candlelight vigils, marathon prayers, and petitions against the construction not only delayed the project, but also led to serious socio-political conflicts between government authorities and social groups over the environmental impact and risks of the project. According to a report from the Korea Chamber of Commerce and Industry, a socio-economic cost of over two billion dollars was incurred as a result of the project delay. ${ }^{2}$

The tunnel construction was a key event that received intense media attention leading to an unusual wave of news within a short period. In particular, the suspension and subsequent resumption of construction triggered an escalated media report on possible environmental risk and counter arguments, and fuelled public concern and social conflict, which, in turn, fed media coverage. In this reinforcing process, online and offline media played critical roles in inducing the upward spiral of media attention for the key event. A series of increasing media hypes showed the amplification process of risk issues. Contrary to assessments by government authorities and experts, the environmental risk from the construction was exaggerated, and became a particular focus of public concern that caused diverse secondary social, political, and economic consequences (Chung, 2011; Kasperson et al., 2000: 235). The Supreme Court finally rejected the environmentalists' appeal in June 2006.

\section{Research data}

Research data were collected from the online edition of Chosun Daily, a major newspaper with the largest daily circulation of over 2.3 million, ${ }^{3}$ and online message boards of public and non-profit organizations' websites, such as the President's Office, Ministry of Environment, Green Korea United, and 


\begin{tabular}{lcr}
\hline \multicolumn{1}{c}{ Organizations } & \multicolumn{2}{c}{ Observations } \\
& (January 1, 2003-June 30, 2005) \\
\hline Chosun Daily & 3,319 comments & (158 articles) \\
Office of the President & 27,141 visits & (567 posts) \\
Green Korea United & 5,842 visits & (84 posts) \\
Buddhist Environmental Solidarity & 21,747 visits & (334 posts) \\
Ministry of Environment & 5,119 visits & (83 posts) \\
\hline
\end{tabular}

Table 9.1. Data collected from online media and websites*

* The website addresses of the organizations from which data were collected are: www.chosun. com (Chosun Daily); www.president.go.kr (President's Office); www.green korea.org (Green Korea United); www.budaeco.org (Buddhist Environmental Solidarity); and www.me.go.kr (Ministry of Environment), respectively.

Buddhist Environmental Solidarity (Budaeco), which were related to the tunnel construction and its environmental impact (Table 9.1). Green Korea United is the largest non-profit organization in the country engaged in environmental protection. Buddhist Environmental Solidarity is a religious organization supporting environmental activists. Newspaper readers' opinions, uploaded to online newspaper articles, and visitors' comments posted on the message boards of government agencies and non-profit organizations, were collected in order to review the amplification process of social attention for the project. An analytical focus is placed on the total numbers of 1 ) comments or talkbacks attached to newspaper articles; and 2) visits to or clicks on message posts on the websites of public or non-profit organizations, rather than those of newspaper articles and message board posts. While newspaper articles and message posts are influenced by newspaper editors and a limited number of active post-uploaders, readers' comments and post visits are assumed to represent society-wide attention or public concern for the issue. ${ }^{4}$

\section{Public attention for the tunnel project}

The social attention for the project or the public concern about the risks involved with the tunnel construction, as measured by newspaper readers' comments and citizens' visits to website posts, shows an amplifying pattern over the observation period. The total number of newspaper articles and website posts, when aggregated monthly, shows a similar intensifying trend (Figure 9.1). It shows a strong correlation $(\mathrm{rho}=.97, \mathrm{p}<.0001)$. This research covers the time frame from 1 January 2003 to 30 June 2005. 


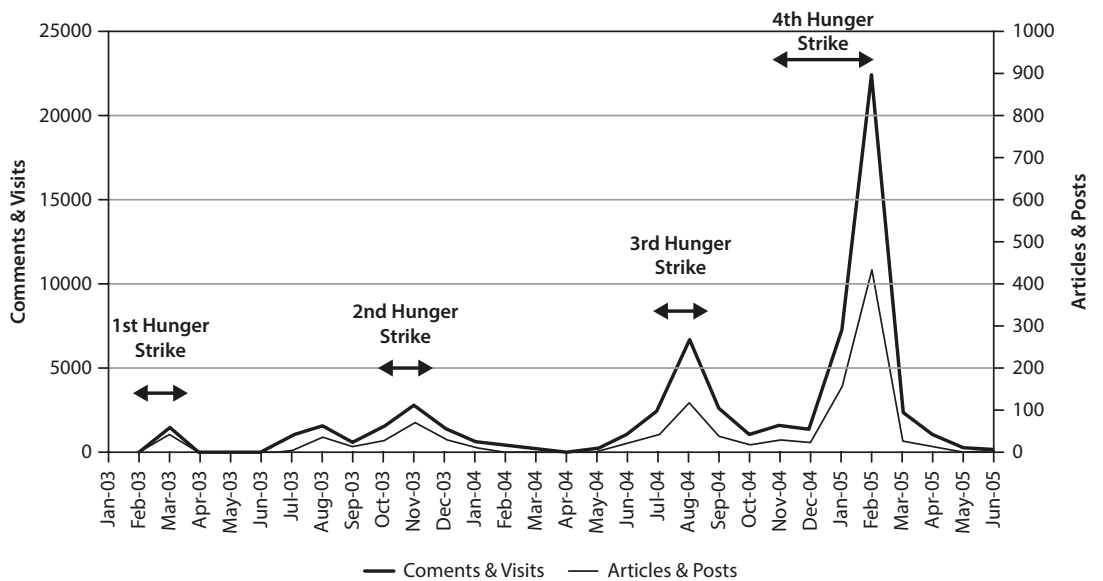

Figure 9.1. Amplification of Public Attention*

* The figure was modified from the original version (Chung, 2011: 1888).

Environmentalists' voices against the tunnel construction have been heard since the project was initiated in 1992. However, they were unable to attract public attention until, in particular, the previously mentioned environmental campaigner Jiyul embarked on active anti-construction activities, including hunger strikes in early 2003. Her hunger strikes triggered and intensified public concern about the issue over the period. Indeed, the highest level of each attention wave corresponded with a hunger strike. The last and the longest 100-day hunger strike, from December 2004 to February 2005, induced the largest volume of newspaper articles, opinions, message board posts, and website visits. After this period, the numbers declined rapidly; that is, the public attention and the social concern about environmental risks faded.

\section{Interactivities of mass media and the public ${ }^{5}$}

Public attention measured at each social station, or online newspaper and website of individual organizations shows a distinctive pattern, different from the overall amplifying process of aggregated public attention. In order to compare public attention to each station, the number of readers' comments on newspaper articles and the number of visits to each organization's website were standardized into z-scores (Figure 9.2). 


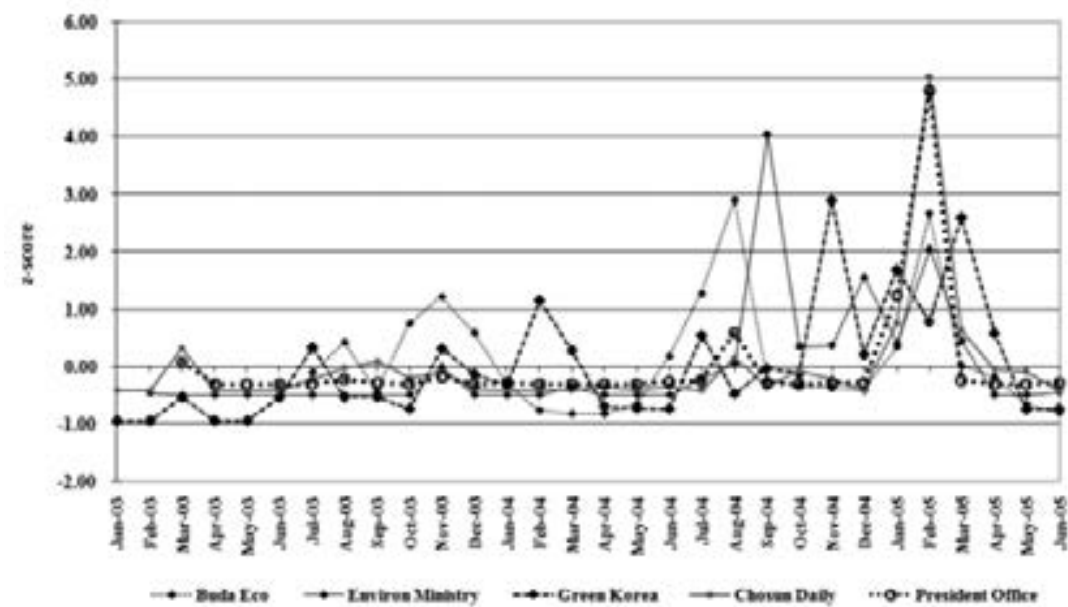

Figure 9.2. Public attention for individual social stations*

*The original version of this figure appears in Chung (2011: 189o).

In early 2003, the public paid limited attention to the tunnel construction project. The Buddhist organization, Budaeco played a watchdog role in terms of protecting the environment near the construction area. As a local and religious organization, Budaeco kept working with major actors against the project. ${ }^{6}$ Its website reflected the activities as well as voices of environmentalists. For example, a minor surge of online visitors' concerns appeared on the website in August 2003 when Jiyul and other activists began an action campaign against the construction. The initial attention seen at Budaeco was followed by waves of public attention with increasing intensity. The public attention on Budaeco's website preceded that seen later on the website of the Ministry of Environment. Budaeco achieved its highest level of public attention during Jiyul's third hunger strike in August 2004. This, in turn, induced intense attention for the Ministry's website in September 2004. However, at this stage, the tunnel had still not fully developed into a national issue. Once Budaeco initiated and amplified public attention in this early period, the level of public attention for its own website began to dwindle. This implies that the website worked as a trigger, raising extended social attention and provoking government action to protect the environment.

As mentioned, the public attention for the Budaeco website shifted to the website of Korea's Ministry of Environment. The number of visits to the Ministry's website reached its highest level in September 2004 when the Ministry was preparing the final Environmental Impact Assessment 
report on the construction. A surge of website visits represented a strong message, asking the administration responsible to preserve the mountain's ecosystem. Just after the Ministry's official announcement that the tunnel would not have a serious impact on the ecosystem, environmentalists, including Jiyul, began a fourth hunger strike in October 2004.

Dissatisfied with the Ministry's formal stance on the tunnel construction, the public no longer relied on the Ministry to stop the project and protect the ecosystem. Instead, Green Korea United, a nationwide non-profit organization with the largest membership in the country, took over an active role, leading activities against the construction. The number of opinion posts and the number of visits to posts on Green Korea's website reached a peak in November 2004. The appearance of a leading environmental organization in the public discussion arena and the convergence of public attention on its website signified a significant change in the risk communication about the tunnel construction. It represented not only a reaction against the Ministry's final decision, but society-wide concern for and pressure against the project.

As the level of public attention for Green Korean increased, as measured by an increase in the number of visitors to its website, and as Jiyul's fourth hunger strike approached 100 days, the number of newspaper articles and comments in response to them also increased rapidly. The peak of public concern on Green Korean's website was followed by highly amplified public attention for the online newspaper, Chosun Daily. Jiyul's prolonged hunger strike induced nationwide concern and diverse activities such as candlelight vigils, religious prayers, resolutions by legislators, and, indeed, hunger strikes by other organizations' members. These activities resulted in social attention reaching its highest level on February 2005. Highly amplified public attention for Chosun Daily reflected a society-wide sense of urgency. The volume and the content of comments in response to news articles pressured the president to stop Jiyul's fast-to-death behaviour. The pattern of attention amplification on the President's Office website was clearly matched by that on Chosun Daily.

Public attention measured on each station's website showed different patterns in terms of time and intensity. Budaeco and Green Korea United had attracted social attention since the early period. In particular, the public attention for Budaeco reached its highest level earlier than the others, in August 2004. Public attention for Chosun Daily and the President's Office remained at lower levels throughout most of the period, until February 2005, and then rapidly increased to the highest level of all organizations reviewed in this study. The temporal sequence of the peak of attention for 
each station was Budaeco in August 2004; the Ministry of Environment in September 2004; Green Korea United in November 2004; and Chosun Daily and the President's Office in February 2005. In contrast to an amplifying process, the social attention for Budaeco, Ministry of Environment, and Green Korea United showed a pattern of ascending impulse waves followed by descending ones.

\section{Analytic framework for media hype}

This study applies the analytical framework for media hype to those periods in which the level of public attention is relatively high or amplified, as measured by the number of newspaper readers' comments and number of visits to websites. The framework is partially modified from the existing one as suggested by Vasterman (2005:522) and the categories have been rearranged in consideration of the research focus of this study. The early framework was intended for generic research on communication; in particular, the media's role in self-reinforcing the process of news production. This means that it is not entirely suited to analysing the interactivities between mass media or online newspapers and the public's response, in the form of news messages regarding risk issues.

The major components or categories of media hype remain unchanged; however, the orders of sub-categories have been adjusted. News articles are classified into two main categories: incident-related news and thematically related news. The first category covers factual reports about actual events, i.e. the key event and similar events. Items included in the 'similar incidents' sub-category are simplified into 'related incidents'. The second category comprises news articles that are thematically related to the key issue or similar incidents. Thematically related news is sub-categorized into source-generated and media-generated reports. The order of sub-categories under 'thematically related news' was transposed.

The sequential location of sub-categories from left to right is: key event; similar incidents; source-generated news; and media-generated news. The last sub-category includes items that are not based on the real event or incidents, but on issues generated or made by media. In addition to rearranging sub-categories, classifications and examples under sub-categories were modified or added to meet the research purpose of this study. In order to reflect public agencies' activities in relation to the risk issue, for example, government policy changes are included in the 'source-generated' sub-category under 'thematically related news'. 


\section{Analysis of media hype}

During the research observation period from January 2003 to June 2005, as plotted in Figure 9.1, there were four times when the level of public attention was relatively high; that is, the public concern about the tunnel construction project was amplified four times, as measured by the number of newspaper readers' comments and people's visits to websites. The analytical lens for media hype is applied to three of these four peaks in the public attention during which the online newspaper, Chosun Daily, intensively covered the issue. One major characteristic of a media hype is 'intense media coverage' of a specific issue (Vasterman, 2005). However, the concept of 'intense coverage' is so relative and subjective that it is not easy for analysts to make a clear decision on the level of coverage intensity (Wien \& Elmelund-Præstekær, 2009: 190). This research analysed those months yielding ten or more news articles. In this case, there were three hypes in the news coverage: March 2003, August 2004, and January and February 2005.

Of 158 newspaper articles with 3,319 readers' comments, collected to analyse the amplifying process of public attention for the tunnel project, a total of ninety-seven articles with 2,198 comments falls into three hypes: twenty-one articles with 202 comments in March 2003; twelve with 154 in August 2004; and 64 with 1,842 in January and February 2005 (Table 9.2). All articles included in these three hypes were read by three reviewers ${ }^{7}$ to classify them into the categories explained in Figure 9.2. Of the twenty-one articles in the first hype, two articles are classified as 'incident-related news' and nineteen articles as 'thematically related news'. The second hype includes twelve articles, of which one is incident-related and eleven articles are thematically related. The third hype with the largest number of observations comprises three incident-related news articles and sixtyone items of thematically related news. During all three hype periods, thematically related news heavily outnumber incident-related news. More

\begin{tabular}{|c|c|c|c|c|}
\hline & March 2003 & August 2004 & Jan. \& Feb. 2005 & Total \\
\hline & Articles / Comments & Articles / Comments & Articles / Comments & \\
\hline Incident-related News & $2(9.5 \%) / 18(8.9 \%)$ & $1(8.3 \%) / 13(8.4 \%)$ & $3(4.7 \%) / 3(0.2 \%)$ & $6 / 34$ \\
\hline Thematically related News & $19(90.5 \%) / 184$ (91.1\%) & $11(91.7 \%) / 141$ (91.6\%) & $61(95.3 \%) / 1,839$ (99.8\%) & $91 / 2,164$ \\
\hline Source-generated news & 15 (78.9\%) / 56 (30.4\%) & $4(36.4 \%) / 38(27.0 \%)$ & $15(24.6 \%) / 321(17.5 \%)$ & $34 / 415$ \\
\hline Media-generated news & $4(21.1 \%) / 128(69.6 \%)$ & 7 (63.6\%) / $103(73.0 \%)$ & $46(75.4 \%) / 1,518(82.5 \%)$ & $57 / 1,749$ \\
\hline Total & $21 / 202$ & $12 / 154$ & $64 / 1,842$ & $97 / 2,198$ \\
\hline
\end{tabular}

Table 9.2. Media hypes and issue amplification 
than ninety-three per cent of news articles are classified as 'thematically related news' in all periods.

As the number of news articles in each hype fluctuated over time, so do the numbers for incident-related news and thematically related news. Moreover, the predominance of 'thematically related news' was also intensified throughout the period. The proportions of 'thematically related news' for the three identified hypes are: $90.5 \%$; $91.7 \%$; and $95.3 \%$, respectively. As expected, the proportion of 'incident-related news' declines continuously from $9.5 \%$ to $8.3 \%$ and then to $4.7 \%$. Within 'thematically related news', in particular, the proportion of 'source-generated news' rapidly decreases over the period. On the other hand, the proportion of 'media-generated news' shows a steady increase from $21.1 \%$ in the first hype to $63.6 \%$ in the second and $75.4 \%$ in the last.

\section{Public response to media hype}

In comparison with media hype as measured by the number of news articles, the number of comments on or replies to news articles as an indication of public response shows a different distribution across the categories. Of 2,198 comments attached to ninety-seven news articles in three hypes, a total of thirty-four comments $(1.5 \%)$ was uploaded to six incident-related news articles and the remaining 2,164 comments (98.5\%) are attached to ninety-one thematically related news items. The proportion of comments to thematically related news $(98.5 \%)$ is higher than those for news articles (93.8\%). During the third hype, in particular, the proportion of comments assigned to thematically related news (99.8\%) is much higher than those posted in response to news articles (95.3\%).

The disproportional distribution of comments becomes intensified for the sub-categories under 'thematically related news'. While the proportions of 'source-generated news' in three hypes are $78.9 \%, 36.4 \%$, and $24.6 \%$, respectively, those of comments uploaded to the news articles are $30.4 \%$, $27 \%$ and $17.5 \%$, respectively. For 'media-generated news, the proportion of news articles increase from $21.1 \%$ to $63.6 \%$ and $75.4 \%$; and in terms of comments on these articles it starts at $69.6 \%$ in the first hype and reaches $82.5 \%$ in the third hype. 


\section{Discussions and conclusion}

Online newspaper and the website message boards of social organizations work as an open arena for risk communication. The internet provides social stations and the public with an efficient means of information sharing and public participation. Without the internet, it is difficult for the public to recognize a risk issue and to express their opinion on it (and in general). Interactions between social stations clearly demonstrated a process of amplifying public attention for the environmental risks related to construction of the tunnel. The peak level of public attention for social stations differed. A growing surge of public concern moved consecutively from Budaeco, the Ministry of Environment, Green Korea, Chosun Daily, and the President's Office. The sequential order of attention waves implied ripple effects of the amplification process in which public attention spread out, having a wide impact on society, beyond that of the key event. The online newspaper played the role of a conduit in this process, connecting society-wide attention represented by Green Korea to the political agenda, represented in this case by the President. It also worked as an opinion reservoir, open for public participation through online comments or talkbacks. Mass media, specifically online newspapers in this study, must be a major social station in the issue amplification process, as emphasized by Kasperson (2000). However, in this case, the analytical framework of risk amplification could not fully explain the specific functions or activities of mass media in the amplification process.

How do online newspapers, more than just a conduit or a reservoir, make and shape issue waves? The research framework of media hype (Vasterman, 2005a) sheds light on this question. According to analyses of three consecutive hypes, not only the number but also the proportion of 'thematically related news' dominated those of 'incident-related news'. As the level of social attention increases or is amplified, the dominance of the former becomes more obvious. In the 'thematically related news' category, in particular, both the number and the proportion of 'media-generated news' increased rapidly, while 'source-generated news' decreased throughout the three hypes. This reconfirms that the media has a strong influence in terms of describing the reality of an issue and transmitting information about it by 'creating stories'.

An academic reason for studying 'media hype' is based on a familiar expectation that a media-generated news wave, or self-inflating media coverage, can attract intensive public attention. This can distort our perception of reality and go against the correspondence assumption (Kepplinger 
\& Habermeier, 1995). The research outcome in this chapter shows that the proportions of newspapers are different from those of comments attached to them throughout the three hypes. The proportion of comments on thematically related news is much higher than those for news articles. In particular, the disproportional distribution of comments becomes even more intensified for the 'thematically related news' sub-categories. This means that more public attention or reaction converges on 'media-generated news' than on 'incident-based news'. Media hypes that are generated from self-inflating or self-referential news coverage could be accelerated by positive feedback loops underlying interactivities between mass media and the public. Higher media coverage leads to intense public attention; at the same time, focused public attention induces strong media attention with a larger volume of news articles.

A longitudinal comparison of three media hypes using data from newspapers, website posts and online comments provided an empirical background for explaining the dynamics of media hype. The analytical focus of this chapter on interactivities of the media and the public could add extra findings to the existing media hype research, which emphasizes a self-reinforcing process of media coverage. In an online communication environment, in particular, the public attention for or reaction to media hype must be a critical factor in explaining the how a media hype starts and what the process of media hype is. The case reviewed in this chapter is in a specific part of the world with its own socio-cultural characteristics. These research findings have limitations in terms of being able to be generalized to other places and cases. However, a review of media hype through the interactive dynamics of the media and the public are certainly applicable as an empirical back-up to future research.

\section{Notes}

1. According to the social amplification of risk framework, amplification stations can include scientists, individuals, social groups, institutions, the mass media, politicians, public agencies, and opinion leaders that generate and transmit risk information via communications channels (Kasperson et al., 2000).

2. Korea Chamber of Commerce and Industry published a report titled 'Evaluation of National Project Failed or Delayed' on May 2005.

3. For a newspaper article to be selected for this research, at least two of the three search terms or Mt. Cheonseong, Jiyul and high-speed railway should appear in its title or story. Of 166 articles that satisfied this search criterion, 
158 articles were selected, and comments attached to them were reviewed. The same process was applied to selecting stories from online message boards on the websites of public and non-profit organizations.

4. Another reason to count the number of opinions, instead of visitors, to newspaper articles is that the number of visitors clicking each article is not available from the newspaper company. An interview with an editorial board member of the newspaper revealed that the total number of people visiting the newspaper remains consistent everyday, unless special issues or accidents take place that attract extra public attention. Thus, the number of newspaper readers' opinions attached to individual articles is assumed to be indicative of the level of public attention for an issue.

5. Chung (2011) provides an empirical analysis of interactivities among social stations in detail.

6. Budaeco began its website service in July 2003. Data about website messages before this service was established is not available.

7. Three reviewers were the author of this paper and two doctoral students whose academic major was in public policy analysis, and who understood the research purpose and the theme of this study. The Inter-coder test results supported their categorization works with Average pairwise per cent agreement: 94.25\%; Krippendorff's Alpha, o.912; and Fleiss' Kapp, o.913.

\section{References}

Ball-Rokeach, Sandra \& Melvin DeFleur (1976). 'A dependency model of mass-media effects'. Communication Research, 3 (1): 3-21.

Baumgartner, Frank, Jones, Bryan \& Beth Leech (1997). 'Media attention and congressional agendas'. In: Shanto Iyengar, Richard Reeves (eds), Do the media govern? Politicians, voters and reporters in America, 349-363. Thousand Oaks, CA: Sage.

Birkland, Thomas (1997). After disaster: Agenda setting, public policy and focusing events. Washington, DC: Georgetown University Press.

Birkland, Thomas \& Regina Lawrence (2009). 'Media framing and policy change after Columbine'. American Behavioral Scientist, $5^{2}$ (10): 1405-1425.

Chung, IkJae (2011). 'Social amplification of risk in the internet environment'. Risk Analysis, 31 (12): 1883-1896.

Cohen, Bernard C. (1963). The press and foreign policy. Princeton, NJ: Princeton University Press.

Dearing, James \& Everett Rogers (1996). Agenda setting. Thousand Oaks, CA: Sage. Elmelund-Præstekær, Christian \& Charlotte Wien (2008). 'What's the fuss about? The interplay of media hypes and politics'. The International Journal of Press/ Politics, 13 (3): 247-266. 
Finlay, Sara-Jane \& Guy Faulkner (2005). 'Physical activity promotion through the mass media: Inception, production, transmission and consumption'. Preventive Medicine, 40 (2): 121-130.

Flynn, James, Slovic, Paul \& Howard Kunreuther (2001). Risk, media and stigma: Understanding public challenges to modern science and technology. London: Earthscan.

Frewer, Lynn, J., Miles, Susan, \& Roy Marsh (2002). 'The media and genetically modified foods: evidence in support of social amplification of risk.' Risk Analysis 22 (4): 701-11.

Ghanem, Salma (1996). Media coverage of crime and public opinion: An exploration of the second level of agenda setting. Austin, TX: University of Texas at Austin.

Kasperson, Roger, Renn, Ortwin, Slovic, Paul, Brown, Halina, Emel, Jacque, Coble, Robert, Kasperson, Jeanne \& Samuel Ratick (2000). 'The social amplification of risk: A conceptual framework'. In: P. Slovic (ed.), The perception of risk, 232-245. London: Earthscan.

Kepplinger, Hans \& Johanna Habermeier (1995). 'The impact of key events on the presentation of reality'. European Journal of Communication, 10 (3): 371-39o.

Kingdon, John (1984). Agendas, alternatives and public policies, New York: Harper Collins College.

Lampi, Elina (2011). 'What do friends and the media tell us? How different information channels affect women's risk perceptions of age-related female infertility'. Journal of Risk Research, 14 (3): 365-380.

McComas, Katherine (2006). 'Defining moments in risk communication research 1996-2005'. Journal of Health Communication, 11 (1): 75-91.

McCombs, Maxwell \& Donald Shaw (1972). 'The agenda-setting function of mass media'. Public Opinion Quarterly, 36 (2): 176-187.

McCombs, Maxwell \& Donald Shaw (1993). 'The evolution of agenda-setting research: Twenty-five years in the marketplace of ideas'.Journal of Communication, 43 (2): 58-67.

Miles, Brian \& Stephanie Morse (2007). 'The role of news media in natural disaster risk and recovery'. Ecological Economics, 63 (2-3): 365-373.

Murdock, Graham, Petts, Judith \& Tom Horlick-Jones (2003). 'After amplifijication, rethinking the role of the media in risk communication'. In: Nick Pidgeon, Roger E. Kasperson, Paul Slovic (eds), The social amplifcation of risk. Cambridge, UK: Cambridge University Press, 156-179.

Muschert, Glenn (2007). 'Research in school shootings'. Sociology Compass, 1 (1): $60-80$.

Pritchard, David \& Dan Berkowitz (1993). 'The limits of agenda-setting: The press and political responses to crime in the United States, 1950-1980'. International Journal of Public Opinion Research, 5 (1): 86-91. 
Sabado, Larry (1991). Feeding frenzy: How attack Journalism has transformed American Politics. New York: Free Press.

Thomson, Joan \& Laura Dininni (2005). 'What the print media tell us about agricultural biotechnology: Will we remember?' Choices, 20 (4):247-252.

Van Aelst, Peter \& Stefaan Walgrave (2011). 'Minimal or massive? The political agenda-setting power of the mass media according to different methods'. The International Journal of Press/Politics, 16 (3): 295-313.

Vasterman, Peter (2005). 'Media-hype: Self-reinforcing news waves, journalistic standards and the construction of social problems'. European Journal of Communication, 20 (4): 508-530.

Vasterman, Peter, Yzermans, Joris C. \& Anja A.J. Dirkzwager (2005). 'The role of the media and media hypes in the aftermath of disasters'. Epidemiologic Reviews, 27 (1): 107-114.

Wahlberg, Anders \& Lennart Sjoberg (2000). 'Risk perception and the media'.Journal of risk research, $3(1): 31-50$.

Walker, Jack (1977). 'Setting the agenda in the US senate: A theory of problem selection'. British Journal of Political Science, 7 (4): 423-445.

Weaver, David, Graber, Doris, McCombs, Maxwell \& Chaim Eyal (1981). Media agenda setting in a presidential election: Issues, images and interest. New York: Westport.

Wien, Charlotte \& Christian Elmelund-Præstekær (2009). 'An anatomy of media hypes: Developing a model for the dynamics and structure of intense media coverage of single issues'. European Journal of Communication, 24 (2): 183-201.

* This work was supported by the National Research Foundation of Korea Grant funded by the Korean Government (NRF-2014S1A5A2A01015821)

\section{About the author}

IkJae Chung is Professor at the Department of Public Administration, Seoul National University of Science and Technology and Research Associate Professor, Department of Public Administration and Policy, Rockefeller College, State University of New York at Albany. He is also Director of the East Asia Program, Center for Policy Research, Rockefeller College, State University of New York at Albany. 
